\title{
An Archaeological Study of Petroglyphs in Chapaqan, Meshgin Shahr, Azerbaijan
}

\author{
Mohammad Mirzaei $^{1}$, Ali Karimi Kiya ${ }^{2}$, Nasrin Alizadeh ${ }^{3}$, Siyavash Abdollahi ${ }^{4}$, Vahid Ebrahimi ${ }^{5}$ \\ ${ }^{1}$ Department of Archaeology, University of Sistan and Baluchestan, Zahedan, Iran \\ ${ }^{2}$ Department of Archaeology, University of Tehran, Tehran, Iran \\ ${ }^{3}$ Departman of Art, Islamic Azad University of Ramsar, Ramsar, Iran \\ ${ }^{4}$ Department of Archaeology, University of Mohaghegh Ardebili, Ardebil, Iran \\ ${ }^{5}$ Department of Archaeology, Islamic Azad University of Miyaneh, Miyaneh, Iran
}

Email address:

mirzaii63@yahoo.com (M. Mirzaei)

\section{To cite this article:}

Mohammad Mirzaei, Ali Karimi Kiya, Nasrin Alizadeh, Siyavash Abdollahi, Vahid Ebrahimi. An Archaeological Study of Petroglyphs in Chapaqan, Meshgin Shahr, Azerbaijan. International Journal of Archaeology. Vol. 4, No. 3, 2016, pp. 31-35.

doi: $10.11648 /$ j.ija.20160403.12

Received: May 17, 2016; Accepted: May 30, 2016; Published: June 14, 2016

\begin{abstract}
Rock arts can be considered as the most ancient representation of human communities' artwork. Studying petroglyphs is a new research trend among the anthropologists, archeologists, ecologists and decorative arts researchers. Chapaqan complex is located in the northwest of Iran in the east part of Meshgin Shahr, a city near a famous river named 'Qarasu'. This complex is divided into two sections in Northern and Southern flanks. The discovered petroglyphs in Chapaqan contain goat (Ibex), deer, grooves and cupules. These petroglyphs are created by a stroking method and located nearby the permanent river of 'Qarasu'. The petroglyphs in Chapaqan have been examined in field and library-based studies and the motifs are categorized into two animal and geometric groups.
\end{abstract}

Keywords: Azerbaijan, Meshgin Shahr, Petroglyphs, Chapaqan

\section{Introduction}

Previous studies about the rock arts stand as witnesses that these artworks are strong evidences in recognizing the cultural background of a society such as their cognitive style, beliefs and social structures. Fortunately, studies in this field are being pursued seriously in all over the world and are among the most interesting and novel fields of studies among anthropologists, archeologists, ecologists and decorative art researchers [7]. The numerous remained petroglyphs all around the world are reflections of human history in the process of growth and intellectual excellence and artistic sense of human societies as these artistic activities are based on human observation, reflection and share those emotions and experiences with others [14]. However, the relation between these monuments and their nearby ancient settlements have not been widely studied in Iran.

In Iran, like other countries around the world, numerous petroglyphs have been discovered. Based on the recent studies, a rock art can be divided into four groups: petroglyphs, pictographs, geoplyphs and cupules or cup marks [14]. Historical art researchers are considering the rock arts as the most important and most mysterious archeological and historical remains and believe that rock arts can be the "common human language" and "the live archive of the history".

The history of rock art studies in Iran dates back thirtyseven years, to when some pictograms were re-discovered by Izadpanah at the Dushe and Mir Mallas rock shelters in the Kuh Dasht region (western Iran) [3]. Unfortunately, no effort has been made to date the petroglyphs of Iran using new scientific methods. Most of the previous dating methods have been made based on archaeological evidence or art styles.

Meshgin Shahr has great prehistoric cultures, and contains numerous petroglyphs in different areas of the city. During $g$ the last 5 years, more than 15 rock art sites have been identified and introduced by the researchers. Chapaqan is one of important site in Eastern Meshgin Shahr that in this paper, 
an attempt is made to study the rock art of mentioned site, providing a general perspective for the reader. Introducing and analyzing of depiction will be important view in this paper. Comparison with other close sites is another our purpose.

Dash complex is near of this site that there are similarities between in two sites. Dash is worked with same authors too.

Documentary of this research used with GIS and Corel Draw soft wares.

\section{Methodology}

Studies on the petroglyphs of "Azerbaijan's Chapaqan complex" was in two forms of field and library. In the field method, through a systematic investigation, the remnants were identified and registered with the GPS and after that the photographed and then drawn with the Corel software. In the library method, all the drawings were reviewed, analyzed and compared with the similar ones.

Like all petroglyphs, the chronology of these artifacts is ambiguous.

\section{Geographical Location}

Chapaqan complex is located in Chapaqan a village in Meshgin Shahr city in Azerbaijan province, Iran, with an elevation of 1200 meters above sea level (Figs. 1 and 2).

Studying Chapaqan complex's petroglyphs began in 2014 with conducted surveys in two sites located on the south bank and north bank (locally known as Suvama Dashi) of the Qarasu River. Rock arts and petroglyphs of this complex are scattered on small rocks and low-lying cliffs around Qarasu River and on the rock shelters. Rock arts as the most primary kind of human arts, which reflect their habitat, subsistence, history, culture and beliefs have always been of interest to researchers. The abundance of rock arts in Northwest of Iran has attracted a lot of attention.

Some of the studies on the rock art of this region are as follows: Arasbaran petroglyphs (Sungun) [9, 10], Arasbaran rock art [11], petroglyphs art on northwest of Iran [9], Shahar Yeri rock arts [2], Arasbaran petroglyphs [4], archeological surveys on Deve Dashi in Zanjan [8] and studying Iran northwest petroglyphs especially Duzdaqi rock reliefs on northwest of Iran [5].

Table 1. The division of Chapaqan Complex petroglyphs (Authors).

\begin{tabular}{lll}
\hline A study of Dash Complex petroglyphs & \\
\hline Motifs & Ibex & Divisions \\
& Deer & 8 \\
Animals & & 1 \\
& $?$ & \\
Human & Groove & 1 \\
Geometry & Cupule & 16 \\
Total & 35 & \\
\hline
\end{tabular}

The motifs are generally divided into two animal and geometric motifs with the majority of cupules. 35 petroglyphs have been identified up to now including 16 cupules, 8 Ibex, 1 deer and 1 groove (Table 1).

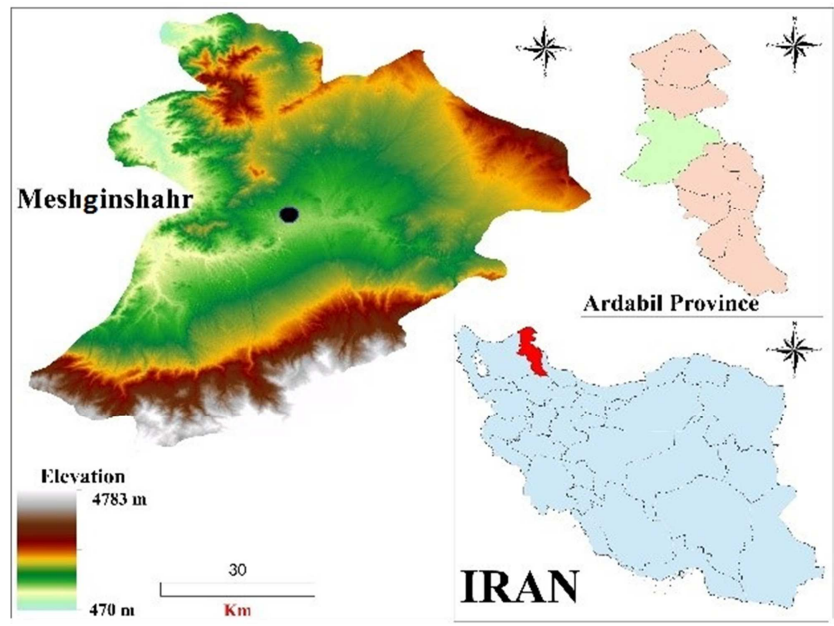

Fig. 1. Chapaqan complex location (authors).
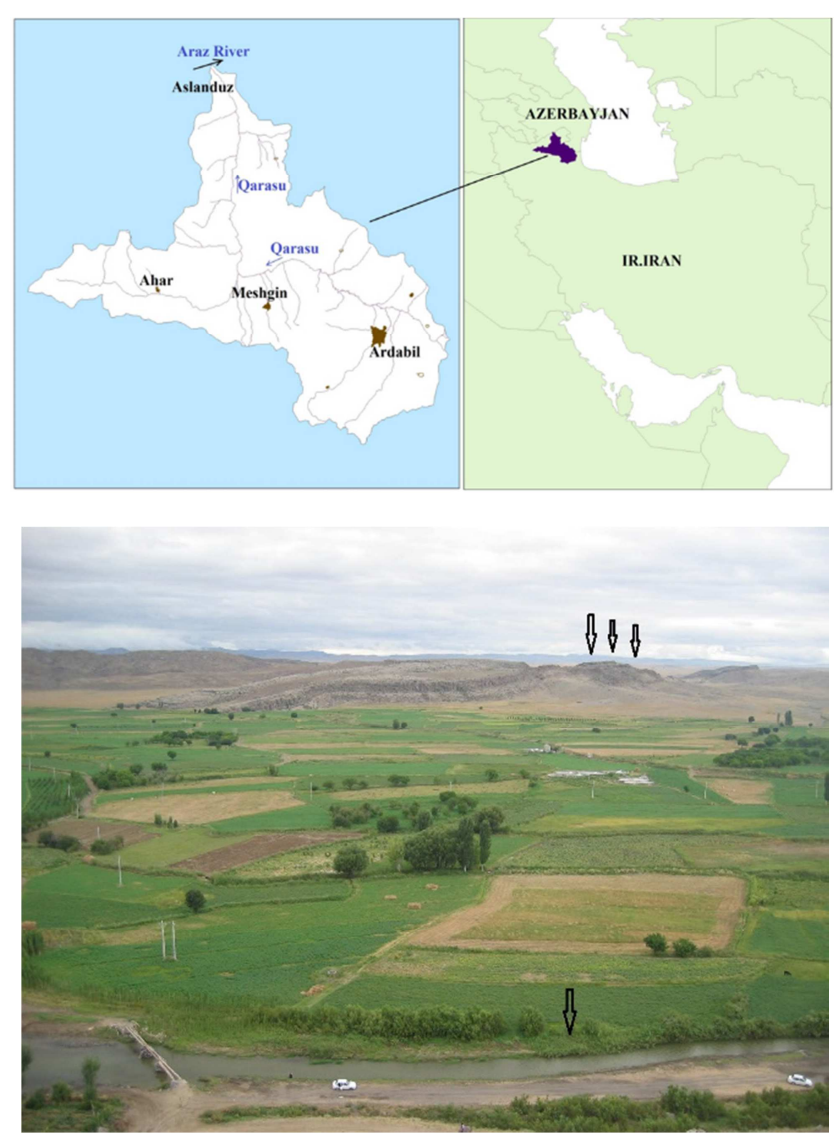

Fig. 2. The catchment position of Qarasu River and situation of Chapaqan complex (authors).

Like most of their kinds, the Chapaqan rock arts are also located nearby a river and usually in the spaces, most of which being created by stroking, carving and constant strikes or scratching the rocks. Their size and depth range from $1 \mathrm{~cm}$ to $30 \mathrm{~cm}$. However, in some cases the depth of the motifs have been so eroded over the time and due to natural factors they have become almost as flat as the rock. Or the color of pictographs is faded and not easily visible anymore. 


\section{Characteristics and Features of the Motifs}

Features and characteristics of the concerned motifs of this study are described here in order to clarify the discussion and propose some criteria for chronology:

- Their location: Chapaqan Petroglyphs are located nearby different water recourses such as seasonal and permanent rivers like Qarasu River and on the low slope cliffs.

- Motifs' techniques: all of the motifs have created by scratching or carving the cliffs. Some of the cliffs are very shallow while others such as cupules are as deep as $30 \mathrm{~cm}$.

- Motifs' quality: the depth, color, erosion and insolubility of the colors are amongst the factors determining the chronology of the motifs and their primacy and recency. As already mentioned, the color and depth of the motifs are different and some of them are almost as flat as the rocks' surface and color are faded by erosion.

- Motifs' size: the size of motifs is varies between $4 \mathrm{~cm}$ to $10 \mathrm{~cm}$.

Existence of settlements and ancient sites dates back to Neolithic until the recent periods in this region can be the main factor in justifying the historical and cultural position of these motifs and their creation date.

Probably only a few number of the surveyed sites on the basin of the Qarasu River are located in the northern complex of Chapaqan. The primary artist were usually occupied with drawing the animals dealing with their daily routine [6] and it is obvious in the petroglyphs of Chapaqan as well. All of the depicted animals are those which were hunted or somehow related to their hunting daily life. In order of frequency, these are ibex, deer, Cupules.

Ibex (Goats): Regarding the documents and evidences and the conducted surveys, this motif is almost depicted in all of the cultural centers of prehistoric periods. The most frequent motif among Meshgin Shahr petroglyphs are ibex (Fig. 3) and cupules which are drawn in stylistic and unnatural ways or in an almost natural style.

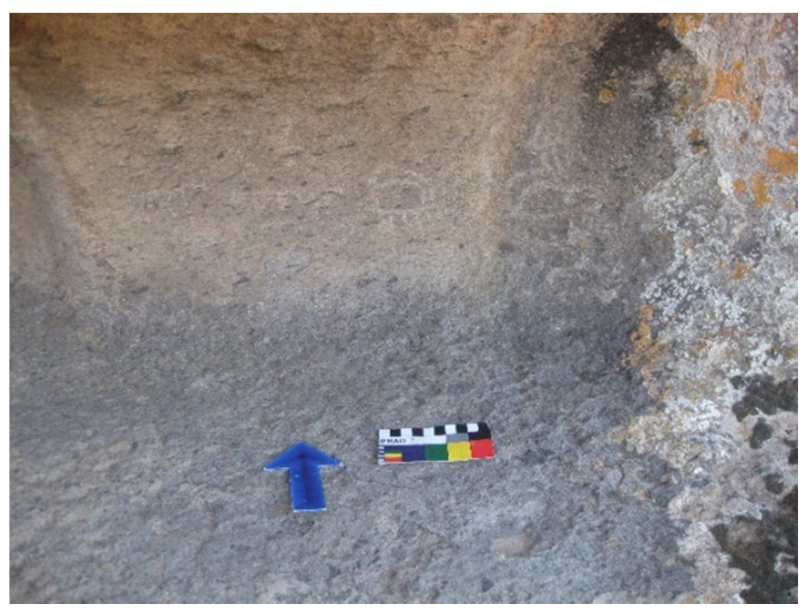

Fig. 3. A few Ibex motifs in Chapaqan complex (Authors).
Deer: Only one motif of a deer is identified among the discovered motifs. The motif is depicted naturally and recognizable by its large horns with $10 \mathrm{~cm}$ length and a realistic style. This motif along with the rest of the motifs in this complex have been oxidized and faded into the surface color.

As these motifs are located in the cold mountainous region of Azerbaijan, factors such as weathering, climate changes, erosion and the passage of time have faded the colors and motifs and cracked the cliffs, destroying some of these motifs or putting them in danger.

Grooves and Cupules: Another featured motifs are the grooves which, like motifs, are carved artistically on the rocks with two cup-like pits on its both ends (Fig. 4).

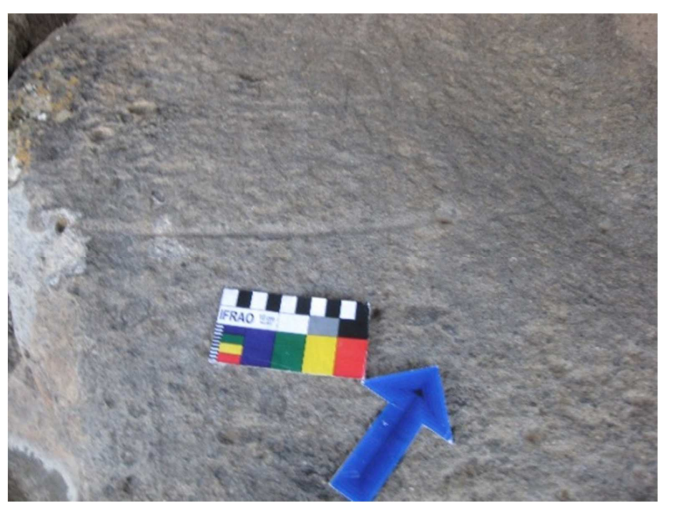

Fig. 4. Groove and two cup like pits on its both ends (Authors).

It is likely that first the cup-like pits had been created and then the groove were connected to them. The same grooves exist in the Dash rock art complex although the Dash complex is deeper and more complicated.

Cupules are the most frequent motifs and scattered all over the site. Besides the cupules, there are spangles like shapes among the motifs as well (Fig. $5 \&$ Fig. 6).

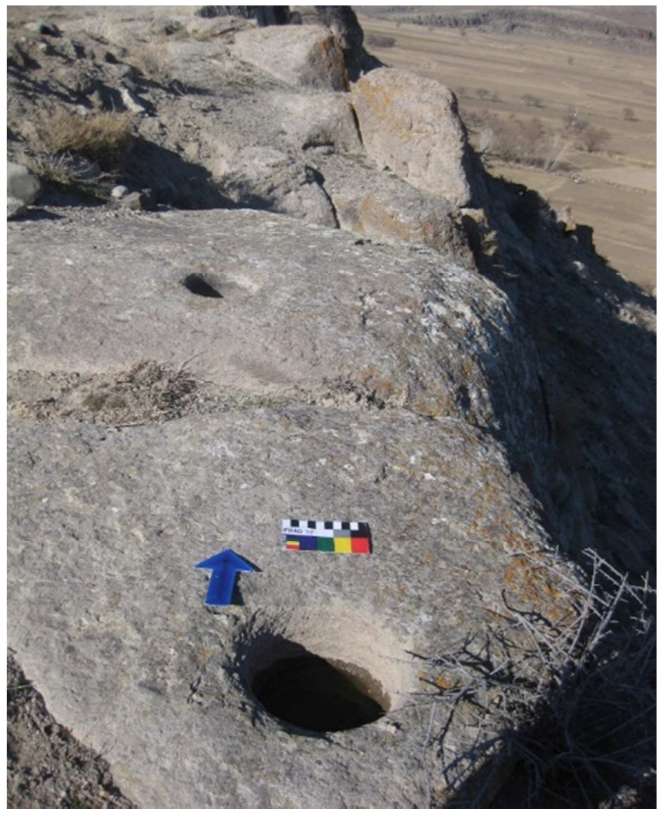

Fig. 5. Cupules in Southern flank of Qarasu (Authors). 


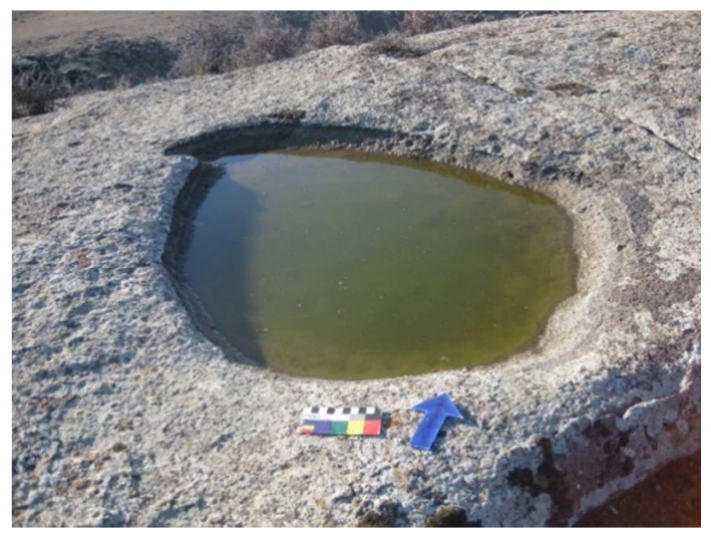

Fig. 6. Cupules in Southern flank of Qarasu (Authors).

One of the best motifs is that this ancient site is a set of spangle shape pits with almost the same size and in an east to west pattern on the north of eagle statue in Chapaqan (Fig. 7). The pattern represents two semi-circles and a diagonal line which passes through it. The same cupules and spangle motifs exist in the dash complex with different depths.

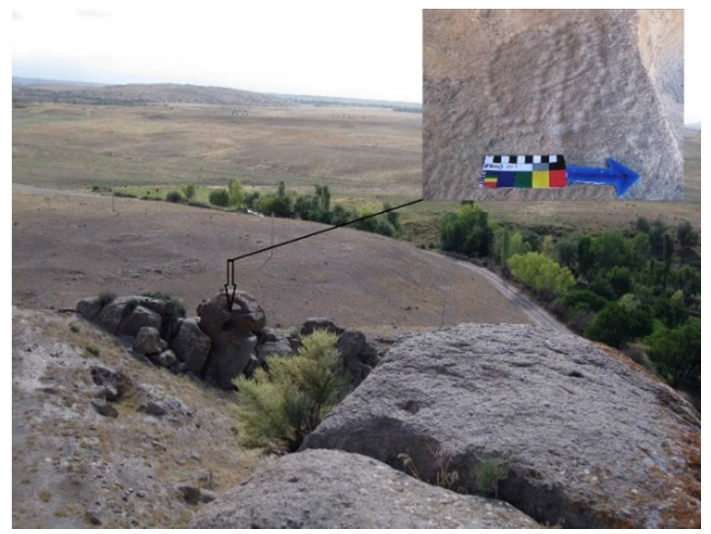

Fig. 7. Especial Cupules in Chapaqan complex (Authors).

The same cupules are discovered in Qobustan site located in the Republic of Azerbaijan as well as other sites in Iran. Researchers believe that, the function of cupules varies from collecting rainfall water to a place for making ritual food, collecting the sacrificial blood, dyeing containers or perhaps even zodiac symbols [1]. We can also consider that a set of forty spangle-like pits might have a numerical function or might be a kind of game.

\section{Chronology}

Lack of precise chronological data is a major obstacle for rock art researchers. They, therefore, have turned their attention to the relative dating. Cupules and two samples of flakes are the best available materials for dating the site. Numerous cupules, several rock shelters and even two flakes of Paleolithic periods are strong evidences of existing settlements in this region. It is very likely that this site is contemporary with Dash complex which is only two kilometers far from Chapaqan site. Another solution for dating this site is to compare the findings of this site with the rock arts and petroglyphs in Qobustan [12] and Gəmi Qaya. Another point to add is that, we believe, the depiction of these motifs is related to the dominant cultural criteria of that time.
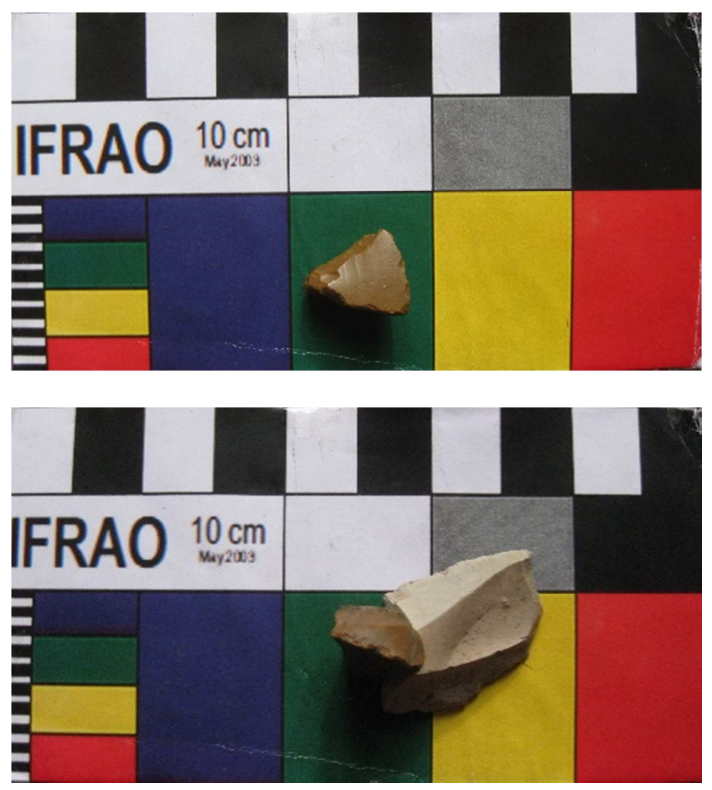

Fig. 8. Two hand axes or Levalloisian point are found in Chapaqan site.

Other thing we can find about the chronology of mentioned site are two hand axes or Levalloisian point.

\section{Conclusion}

Archeological artifacts and cultural remains of Azerbaijan region are still widely unknown and intact which provide a wide scope of research area for scholars, historians and archeologists to achieve valuable information about human ancient history. Qarasu river basin with its specific and strategic location had had a special position among the local communities. Besides the ancient tepes in the basin of this river, other findings such as the rock art complexes of the flat rocks or huge cliffs have also great importance for archeologists as the animal motifs in these complexes say a lot about the livelihood of their habitants and the environmental conditions of the site. The Chapaqan rock arts located in Chapaqan village are one of these important complexes. Its motifs contain animal, symbolic and geometric figures in the majority though other motifs have been identified in this site. Many scenes have been identified among these motifs which can have special meaning and represent a specific symbol. We can conclude that the motifs in the northwest of Iran are related to the motifs in the north of Aras River, especially Qobustan complex in Azerbaijan and other similar sites in Iran. Compared to previous studies in this field, there is a close similarity between the motifs found in the northwest regions and Qobustan region in their content and drawing style. Therefore, based on the precise dating in Qobustan and comparison the motifs of these two sites with identified motifs in Qarasu basin, one can argue that they can be dated from Paleolithic to the contemporary periods. Regarding the current evidences, Qarasu rock motifs 
have a rich background in terms of settlements and different groups of residents in this region. Moreover, they can be related to communities and groups who were experiencing the gradual livelihood changes from nomadism and hunting to animal husbandry and sedentism. Therefore, compared with other rock motifs in the Qarasu basin such as Shahar yeri motifs, Mashiran, Deveh Deresi, Sheikh Medi and specifically Dash complex, it can be concluded that the mentioned motifs in this study are also remains of the prehistoric periods continued up to the contemporary time in an imitative way and with special characteristics.

\section{References}

[1] Fərəcova, Məlahət, 2007, «Qobustan Çalaları», Azerbaycan dövlət nəşriyyatı, bak1.

[2] Hurshid, Shaghayegh, 2007, Introducing Shahar yeri Petroglyphs (Arjaq Castle), Ancient Studies Journal. 3.

[3] Izadpanah H. 1969. Prehistoric paintings in caves of Lorestan. Iranian Archeology and Art Journal 4: 6-14 (in Persian).

[4] Karimi, F, 2012. Arasbaran Petroglyphs. M. A Dissertation of Art History, Islamic Azad University, Shabestar Branch, Eastern Azerbaijan.

[5] Kazempur. M, Eskandari. N, Shafizade A, 2011, The petroglyphsof Dowzdaghi, Northwestern Iran, Documenta Praehistorica XXXVIII, Pp 383-387.
[6] Laura Goran, Andre. Known and unknowns in art history. Translated by Nourladin Farhikhte. Pousheh, Bija, Bita publication.

[7] Naseri Fard, Mohamad, 2007. Stone Museums, rock arts (Iran's petroglyphs). Arak: Navay-e Danesh Publication.

[8] Nurullahi, Ali, and Sara Alilou, 2011, Shepherding in the northwest: The petroglyphs of Gery Kouh (two horses) at the foot of Zanjan Mountain, The Culture of Zanjan Journal, The Culture and Islamic Guidance Organization, Issue no. 31-32, pp 73-103.

[9] Rafiefar, J, 2002, Arasbaran Petroglyphs (Sungun). Anthropology Journal. 1 (1). P 44-75.

[10] Rafiefar, J, 2005, Arasbaran Petroglyphs. Tehran: Anthropology Research Institute publication.

[11] Rafiefar, J, 2009, Rock Art in Northwestern Iran, Hurans (Laqlan) Petroglyphs. Archeology, Research Institute publication.

[12] Rüstəmov C. (1994), Qobustan dünyası, Azərnəşr, Bak1, s. 173.

[13] Sinay, Sue, Anne, 2001, «Rock Art Native American Indians Southern California», Manhattan Beach. California, USA.

[14] Tolstoy, Leo, 1977, What's Art? (Trans. Dehgan, K). Tehran: Amirkabir. 